\title{
Análise do Desenvolvimento da Tecnologia de FCC sob a Ótica das Teorias de Aprendizagem Organizacional e Dinâmica da Inovação*
}

\author{
Luiz Fernando Leite \\ Doutorando da Escola de Química da UFRJ, coordenador de tecnologia do \\ Complexo Petroquímico do Rio de Janeiro - Petrobras \\ Peter Seidl \\ Doutor em Ciências e professor da Escola de Química da UFRJ \\ Adelaide M. de Souza Antunes \\ Doutora em Ciências e professora da Escola de Química da UFRJ
}

\section{RESUMO}

É apresentado o histórico do desenvolvimento da tecnologia de Craqueamento Catalítico Fluido pela Petrobras, cuja trajetória de construção de conhecimento compreendeu quatro fases: aprendizado, aquisição, consolidação e domínio. As primeiras etapas da trajetória tecnológica, que compreendem as fases de aprendizado e aquisição, são analisadas segundo Modelos de Aprendizagem Organizacional consagrados, tais como os de Nevis, DiBella e Gould; Huber; e Senge, sendo verificado para qual desses modelos há uma aderência maior da trajetória de aprendizado da Petrobras. As etapas finais do processo, fase de consolidação e domínio, são analisadas sob a ótica dos Modelos de Dinâmica da Inovação. É feito um levantamento dos distintos modelos descritos na literatura: modelos lineares - ofertista e linear reverso; modelos complexos - terceira, quarta e quinta geração do processo de inovação, Kline e Rosenberg; Utterback; Kim; e Nonaka

\footnotetext{
* Os autores agradecem os enriquecedores comentários e questionamentos dos pareceristas da RBI, que muito contribuíram para uma melhor clareza, objetividade e qualidade técnico-científica deste artigo.
} 
e Takeuchi. É analisada também a trajetória de evolução tecnológica de países em desenvolvimento, da operação à inovação, e verificado a qual modelo a trajetória de inovação tecnológica da Petrobras mostrou melhor adequação. São realçadas também algumas estratégias que contribuíram para o sucesso do desenvolvimento dessa tecnologia.

Palavras-Chave | Aprendizagem Organizacional; Modelos de Dinâmica da Inovação; Gestão de P\&D; Trajetória Tecnológica; Craqueamento Catalítico Fluido $(F C C)$

Códigos JEL | L71; O32

\section{ABSTRACT}

The technological background of Petrobras in Fluid Catalytic Cracking area is shown, as well as its building knowledge pathway, which encompasses four phases: operational learning; acquisition; consolidation; and mastery. The first stages of this technological evolution route, the operational learning and the acquisition phases, were analyzed according to well known Organizational Learning Models, such as those of Nevis, DiBella and Gould; Huber; and Senge, being checked to which model the company learning pathway fits better. The final stages of the evolution process, the consolidation and the mastery phases, are analyzed from the point of view of Dynamic Innovation Models. A survey of these models is made, from the linear ones - technology push and market pull; to more complex ones - Kline and Rosenberg, third, fourth and fifth generation of innovation process; and dynamic models - Utterback; Kim; Nonaka and Takeuchi. The technology evolution pathway for developing countries - from operation to innovation - is also analyzed then discussed and checked to which model the Petrobras innovation route shows better fitness. Some strategies that have significantly contributed to the success of the FCC technology are pinpointed.

KeYWORDS | Organizational Learning; Dynamic Innovation Models; R\&D Management; Technological Pathway; Fluid Catalytic Cracking (FCC)

\section{JEL-CODES I L71; O32}




\section{Introdução}

O Craqueamento Catalítico Fluido (Fluid Catalytic Cracking - FCC) é a principal unidade de conversão do refino, existindo pelo menos uma unidade dessa tecnologia no esquema de processamento de todas as refinarias brasileiras. Desde o início, na fase de montagem do seu parque de refino, a Petrobras se preocupou em adquirir conhecimento sobre essa tecnologia de modo a operar bem essas unidades. Posteriormente, buscou capacitar-se no processo de modo a otimizá-lo e aumentar a rentabilidade do refino, até atingir uma fase de experimentação e maturidade nesse processo produtivo, atuando inclusive na produção do catalisador de FCC. A empresa realizou, ao longo do tempo, diversos desenvolvimentos tecnológicos, aprimorando praticamente todos os equipamentos e sistemas que compõem o núcleo dessa unidade, até dispor de um projeto próprio do conversor de FCC. Atualmente detém o conhecimento total e integrado sobre essa tecnologia nas áreas de $\mathrm{P} \& \mathrm{D}$, projeto conceitual, engenharia de processo e equipamentos, execução de empreendimentos, formulação e fabricação de catalisadores, operação, manutenção, inspeção e acompanhamento de unidades operacionais.

Tomando o conceito de trajetória tecnológica, que foi apresentado por Dosi (1982), como a rota de progresso de um paradigma tecnológico, sendo este definido como uma estrutura de referência, um conjunto de procedimentos, a definição de problemas relevantes e o conhecimento específico relativo à sua solução na aplicação ao meio produtivo e ao mercado, e considerando também a argumentação de Dosi (1988) e Tidd, Bessant e Pavitt (1997) de que inovação tecnológica é dependente da instituição, ou seja, como afirmam estes últimos, “do jeito que fazemos as coisas aquil”, portanto é um processo específico e peculiar para cada companhia (firm-dependent), é apresentado neste trabalho a trajetória de desenvolvimento tecnológico, na área de FCC, trilhada pela Petrobras. Essa trajetória basicamente se divide em duas grandes etapas: a primeira, em que predominou a aquisição e assimilação de conhecimento externo; e a segunda, em que houve intensa transformação e geração interna de conhecimento, visando à inovação. Por conseguinte, a metodologia de análise do processo de desenvolvimento da tecnologia de FCC pela Petrobras adotará duas abordagens distintas: para a fase inicial, é verificado 
para quais modelos teóricos existentes de aprendizagem organizacional a experiência vivenciada por essa organização se coaduna melhor; para a segunda fase dessa trajetória, é verificada a aderência da experiência da Petrobras aos modelos de dinâmica da inovação consagrados na literatura, ou seja, a que conceitos, estrutura e macrofluxo se adequa melhor o processo de desenvolvimento tecnológico percorrido pela Petrobras.

Este trabalho inicia com a apresentação da fundamentação teórica, baseada nos modelos de aprendizagem organizacional e nos modelos de dinâmica da inovação, depois descreve o objeto de análise, que é a trajetória de desenvolvimento da tecnologia de FCC na Petrobras. É proposta uma metodologia de análise e finalmente discutido para quais modelos a experiência vivenciada por essa empresa apresenta melhor aderência.

\section{Fundamentação teórica: Modelos de Aprendizagem Organizacional}

As organizações são arranjos complexos de pessoas, nos quais ocorre a aprendizagem. A necessidade de renovação e transformação organizacional, para o atendimento efetivo do mercado, incita a melhoria da aprendizagem e estimula a busca da inovação tecnológica. Os processos de aprendizagem e inovação tecnológicas se diferenciam, pois o primeiro trata da assimilação e da aplicação de um conhecimento existente, normalmente pertencente a terceiros, enquanto no segundo caso está sendo gerado um novo conhecimento ou se está aplicando de um modo inovador um conhecimento já existente.

O período contemplado neste estudo é longo, indo de 1970 - quando o parque de refino nacional se estabelecia e a ênfase era a multiplicação e o preparo das equipes para assimilar a tecnologia de operação e o gerenciamento das unidades comerciais - até os dias de hoje - quando a Petrobras detém o domínio total da tecnologia -, portanto muitos conceitos modernos de Gestão do Conhecimento e de Gestão da Inovação sequer existiam no início desse processo.

\subsection{As organizações como sistemas de aprendizagem}

Selecionamos três visões e Modelos de Aprendizagem bem aceitos e citados na literatura, os quais foram formulados por Nevis, DiBella e Gould; Huber; e Senge. 


\subsubsection{Sistemas de aprendizagem}

Segundo Nevis, DiBella e Gould (1995), o processo aprendizagem organizacional tem três estágios identificáveis:

- aquisição de conhecimento - o desenvolvimento ou criação de habilidades, insights e relacionamentos;

- compartilhamento do conhecimento - a disseminação do que foi aprendido;

- utilização do conhecimento - a integração da aprendizagem de tal modo que se torne amplamente disponível e possa ser generalizada para novas situações.

Entretanto a aprendizagem nem sempre ocorre de modo linear e pode ocorrer de forma planejada ou informal, freqüentemente não intencionada. Além disso, a aquisição de conhecimento e habilidades também ocorre nas etapas de compartilhamento e de utilização.

As organizações só aprendem através de indivíduos que aprendem. O desafio é transformar a aprendizagem num fenômeno em nível de sistema, pois deve permanecer dentro da organização, mesmo que as pessoas mudem. As organizaçóes aprendem à medida que produzem e para esses autores os sistemas de produção devem ser vistos como sistemas de aprendizagem. Três fatores são muito importantes para o sucesso da aprendizagem:

- competências essenciais bem desenvolvidas que servem como ponto de partida para novos serviços e produtos;

- atitude que apóie a melhoria contínua na cadeia de valores agregados do negócio;

- capacidade de renovar e se revitalizar.

Por outro lado, Huber (1991) identifica quatro estágios ligados à aprendizagem: aquisição, distribuição de informação, interpretação da informação e memória organizacional, estando implícito no modelo a linearidade. A maioria dos estudos sobre aprendizagem organizacional se preocupa com a aquisição de conhecimento e, em grau menor, com o compartilhamento ou disseminação 
do conhecimento adquirido - transferência de conhecimento. Esse autor reforça a importância do processo de assimilação - a interpretação da informação, o modo que o novo conhecimento é incorporado pela organização.

Sendo fornecidas as mesmas informações, adotados os mesmos procedimentos e cuidados na transferência do conhecimento, duas empresas do mesmo setor assimilariam e utilizariam esse conhecimento de modo distinto. A aprendizagem é um processo dependente do conhecimento acumulado, quer seja científico-tecnológico, quer seja mercadológico-comercial. Altamente influenciado pela experiência e práticas operacionais e gerenciais de uma organização, sem falar na cultura e valores que a permeiam. Tidd, Bessant e Pavitt (1997) constataram que os processos de aprendizado e inovação são processos específicos e peculiares para cada companhia. Um conhecimento, ao ser transferido, sofre variaçõos em sua assimilação e utilização. Quando o conhecimento se torna institucionalmente disponível e não mais propriedade de determinadas pessoas ou grupos e é efetivada a sua aplicação, pode-se dizer então que passou a compor a "memória organizacional".

A maneira que a assimilação e a utilização se efetivam na organização é determinante para que a evolução desse novo conhecimento venha a gerar posteriormente uma inovação. Argyris e Schön (1978) dão ênfase à aprendizagem em dois loops e Senge (1990), à aprendizagem geradora (generative learning), sendo o foco desses teóricos a aprendizagem necessária para fazer mudanças de transformação - mudanças de suposições básicas - que as organizaçôes necessitam no ambiente volátil e competitivo de nossos dias.

\subsubsection{As organizações que aprendem (The learning organizations)}

Peter Senge argumenta que uma organização deve constantemente propiciar aos seus membros que expandam sua capacidade de criar os resultados almejados. Novos e enriquecedores padrôes de pensamento devem ser cultivados, nos quais a aspiração coletiva é livremente desenvolvida e as pessoas, continuamente, aprendam a compartilhar a visão do todo.

Para uma empresa se tornar uma learning organization, deve incorporar as cinco disciplinas de aprendizagem, que são: domínio pessoal - expandir as capacidades pessoais para obter os resultados desejados e criar um ambiente 
empresarial que estimule todos os participantes a alcançar as metas escolhidas; modelos mentais - consistem em refletir, esclarecer e melhorar a imagem que cada um tem do mundo, a fim de verificar como moldar atos e decisões; visão compartilhada - o engajamento do grupo em relação ao futuro que se busca e a elaboração de princípios e diretrizes que viabilizarão esse futuro; aprendizado em equipe - desenvolver as aptidóes coletivas ligadas ao pensamento e a comunicação, de modo que grupos possam desenvolver inteligência e capacidades maiores que a soma dos talentos individuais; pensamento sistêmico é criar uma forma de analisar e uma linguagem para descrever e compreender as forças e inter-relações que modelam o comportamento dos sistemas.

Este é o conceito fundamental do livro A quinta disciplina, de Senge (1990), que se baseia na teoria de sistemas cuja principal vantagem é considerar e englobar o todo, buscando o inter-relacionamento entre as partes, o que incentiva a integração das disciplinas. $\mathrm{O}$ pensamento sistêmico permite mudar os sistemas com maior eficácia e agir mais de acordo com os processos do mundo natural e econômico. Nesse livro, é enfatizado o compartilhamento da visão, o trabalho em equipe, a maestria pessoal e o desenvolvimento de modelos mentais mais complexos que devem ser aprimorados através do diálogo, permitindo que o ambiente de trabalho se torne um local de melhor convívio e estimulante à criatividade.

\subsection{Modelos de dinâmica da inovação}

Há um número diversificado de modelos teóricos de inovação que apresentam naturezas distintas, pois alguns são orientados à análise da gestão da inovação, outros ao processo de inovação (etapas, agentes e inter-relações), além daqueles mais focados na economia da inovação. É apresentado um panorama geral, em ordem cronológica, dos modelos mais discutidos na literatura especializada.

\subsubsection{Modelos lineares quanto ao grau de autonomia da atividade inventiva}

No modelo chamado de Ofertista (Science Push ou Technology Push), a inovação é concebida como o resultado de um processo de geração de conhecimentos que vai desde a pesquisa básica, que é um modo de produzir conhecimentos científicos, até a sua aplicação prática, quer dizer, a inovação é 
induzida pela oferta de conhecimentos. Rothwell (1994) considera esse modelo de oportunidades tecnológicas como predominante no período após a Segunda Grande Guerra até a metade dos anos 1960, nos EUA, classificando-o como a Primeira Geração do Processo de Inovação.

Por outro lado, no modelo Linear Reverso (Market Pull ou Demand Pull), a inovação é induzida pelas necessidades de mercado ou problemas operacionais observados nas unidades produtivas, tendo no mercado a fonte das idéias que norteiam as atividades de $\mathrm{P} \& \mathrm{D}$, o qual desempenha um papel meramente reativo. Rothwell (1994) classifica-o como o modelo da Segunda Geração do Processo de Inovação, prevalecente no período compreendido entre a metade dos anos 1960 e o início dos 70.

\subsubsection{Modelo de Terceira Geração}

O modelo de Terceira Geração tenta incorporar essas duas concepções opostas e tem o mérito de mostrar que inovação é um processo que articula as necessidades da sociedade e do mercado com os avanços científico-tecnológicos. $\mathrm{O}$ modelo combinado mostra ainda que as inovações realizadas pelas empresas também contribuem para atualizar o estado da arte. Convém lembrar que os modelos lineares concebem o fluxo de conhecimento apenas num único sentido, do sistema de ciência e tecnologia para a empresa, o que de modo algum é correto (Barbieri \& Álvares, 2003).

Esse modelo pode ser considerado logicamente seqüenciado, embora não seja necessariamente contínuo, podendo ser dividido em uma série de distintas funcionalidades com etapas de interação e interdependência. A trajetória genérica do processo de inovação pode ser concebida como uma complexa rede de comunicação intra e extra-organizacional, interligando várias funções internas e conectando a empresa à ampla comunidade científico-tecnológica e ao mercado. Em outras palavras, o processo de inovação representa a confluência entre a capacitação tecnológica e as demandas do mercado dentro da estrutura inovadora empresarial (Rothwell, 1994).

O modelo de inovação de Terceira Geração foi muito aplicado pelas empresas ocidentais, do início dos anos 70 até a metade dos anos 80, período das crises de petróleo e estagflação, em que o foco estratégico se concentrou no controle e na redução de custos. 


\subsubsection{Modelo de Kline e Rosenberg}

Esses teóricos desenvolveram um modelo que enfatiza as interações entre as fases do processo, como mostra a Figura 1. Na base está o que os autores denominam de cadeia de inovação, formada pela vinculação entre as necessidades de mercado, invenção ou projeto analítico, projeto detalhado e teste, reprojeto e produção, distribuição e mercado. As linhas interrompidas entre os elementos dessa cadeia significam que essas etapas não possuem limites rígidos, havendo permeabilidade entres elas. As setas cheias dentro da cadeia central mostram o caminho típico e as setas interrompidas, as retroalimentaçóes essenciais do processo de inovação. Há três tipos de retroalimentações: as que ocorrem entre os elementos da cadeia, representados pelas setas circulares; os aperfeiçoamentos no produto, o que requer trabalhos em um ou mais estágios ao longo da cadeia, como indicam as setas interrompidas finas; e a vinculação com o planejamento, por meio da avaliação do produto em termos da sua capacidade de alcançar os objetivos mercadológicos, indicados pela seta interrompida grossa.

FIGURA 1

Modelo de Kline e Rosenberg

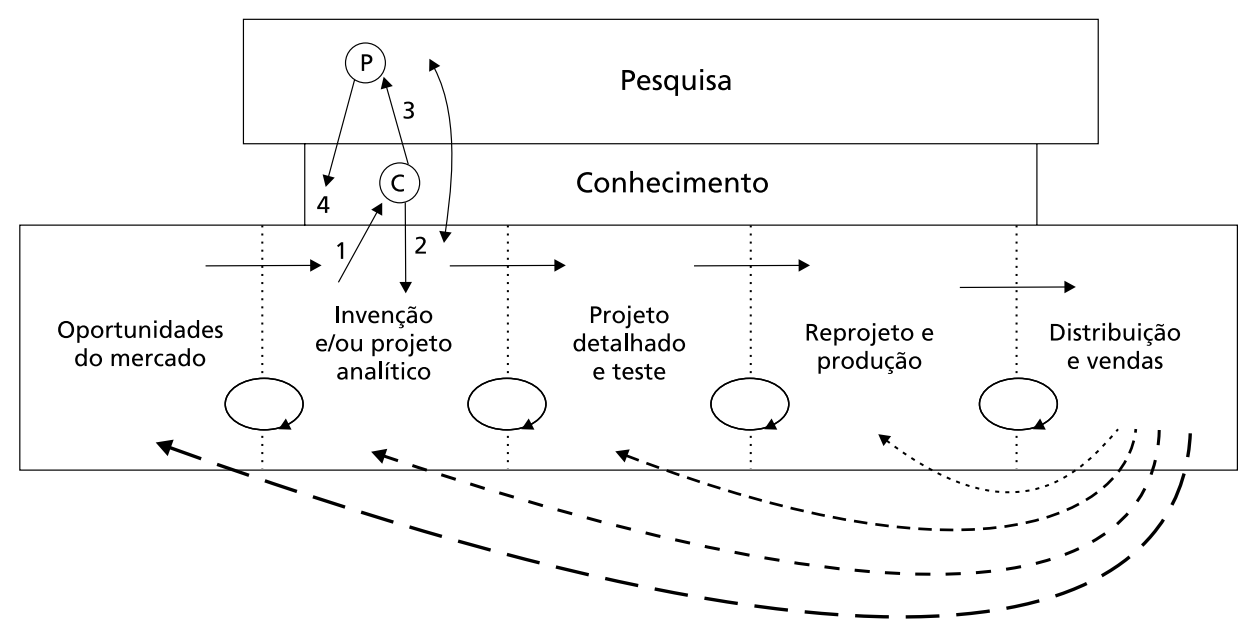


As setas numeradas de 1 a 4 mostram as típicas interações entre invenção, conhecimento e pesquisa: a seta 1 indica a relação entre a invenção e o conhecimento do setor. Se o conhecimento existente é capaz de prover dados, teorias e conceitos, a informaçãa retorna ao processo de invenção, conforme indica a seta 2. Se isso não for possível em nenhuma fonte de conhecimento existente, torna-se necessário realizar pesquisas, o que é indicado pela seta 3. O retorno da pesquisa pode ocorrer num longo espaço de tempo, por isso é indicado pela seta interrompida 4. Esse esquema se repete para as fases seguintes, projeto detalhado e reprojeto, formando vários caminhos de interações que envolvem todos os elementos (Kline, 1978; Kline \& Rosenberg,1986).

O modelo de Kline e Rosenberg mostra que as relações entre as pesquisas científicas e tecnológicas e os processos de inovação se dão em todos os sentidos e com todos os elementos da cadeia de inovação. Esse modelo, embora pareça mais próximo à realidade das inovações, ainda apresenta algumas limitações, pois as atividades são apresentadas independentemente dos agentes e nada transparece sobre a organização interna da empresa inovadora.

\subsubsection{Modelo de Quarta e Quinta Geração}

O modelo de Quarta Geração foi basicamente desenvolvido pelas empresas japonesas que praticavam relaçóes JIT (just-in-time) com seus fornecedores primários e adotaram processos de produção orientados para TQM (Total Quality Management). A integração e o desenvolvimento em paralelo aplicado ao sistema de desenvolvimento de produto, o que foi apelidado de abordagem "rúgbi", propiciaram uma maior rapidez e eficiência na geração de novos produtos. Além disso, o envolvimento dos diferentes departamentos, logo no início do projeto, contribui para uma maior eficiência produtiva, através do "projeto voltado para a manufaturabilidade". Não entraremos em maiores detalhes sobre o assunto, pois não houve uma influência determinante desse modelo para o caso em estudo.

O modelo de Quinta Geração é uma evolução do precedente, no qual o acesso ao know-how externo e o envolvimento com usuários líderes (leadingedge users) passaram a ser essenciais, na tentativa de reduzir a curva de Custo de Desenvolvimento versus Prazo de Desenvolvimento. Por ser um modelo 
mais recente, a literatura a respeito é um pouco difusa. Entre os fatores que são determinantes para seu sucesso, podemos citar: apoio e comprometimento da gerência de topo; adequada preparação - mobilização de pessoas e recursos; alta qualidade da especificação inicial do produto - poucas mudanças inesperadas; uso de times de desenvolvimento integrados; flexibilidade no design - economia de escala e escopo; laços fortes com supridores primários; acesso a know-how externo; e envolvimento de usuários líderes nas atividades de concepção e desenvolvimento (Rothwell, 1994).

\subsubsection{Modelo de Utterback}

Utterback (1996) propóe um modelo que descreve a dinâmica da inovação de produtos industriais montados e não-montados, expondo a mudança de ritmo de inovação do produto, do processo de fabricação e alterações na estrutura organizacional decorrentes da evolução do processo de inovação. É feita uma divisão temporal do processo de inovação, com o foco no mercado, em três fases: fluida, transitória e específica. Para a análise que o autor se propõe, que é centrada na mudança organizacional de uma empresa criada em torno de uma inovação, a divisão proposta é muito apropriada. O modelo descreve as transformações que experimentam as organizações empreendedoras à medida que crescem e são bem-sucedidas, mudando seu enfoque da busca do produto inovador para a produção em massa de produtos padronizados de alta qualidade e custo competitivo. $\mathrm{O}$ modelo, ao definir padrões de inovação para produto montado, mostra que as inovações do produto são independentes das inovaçôes do processo produtivo. $\mathrm{Na}$ medida em que o mercado adota um projeto dominante, a taxa de inovação do produto diminui, tendendo a cristalizar suas funcionalidades e características. Por outro lado, a taxa de inovação na vertente processo aumenta, de modo a se obter maiores ganhos de eficiência e produtividade. No caso do produto não-montado, a taxa de inovação do processo rapidamente supera a taxa de inovação do produto, na busca de uma tecnologia mais robusta e competitiva.

Esse modelo, que também é linear, representa bem a trajetória de empresas geradas a partir de uma inovação. Como todo modelo linear, está um tanto anacrônico para representar as atuais empresas inovadoras, cujo foco 
de sustentação é uma política de lançamento contínuo de novos produtos, em que uma nova plataforma tecnológica é geradora de diversos novos produtos e, através de alianças e da busca de competências complementares, é viabilizada uma série de inovações. Além disso, a automatização e o controle dinâmico de processo fazem com que a fase artesanal se abrevie, o tempo de lançamento de novos produtos se encurte, a customização em massa seja uma realidade. Hoje, passa-se da fase de prototipagem direto à produção em alta escala. O produto não espera o mercado amadurecer, tornando o conceito de marketing de Theodore Levitt (1975) mais presente que nunca. A empresa está constantemente matando e substituindo o seu próprio produto, antes que a concorrência o faça.

\subsubsection{Modelo de Nonaka e Takeuchi}

Nonaka e Takeuchi (1997) abordam a criação do conhecimento, de maneira a fomentar a inovação de modo contínuo, incremental e em espiral, ou seja, buscando conquistar níveis ontológicos superiores na organização. Refletem a visão japonesa do conhecimento que abrange ideais, valores e emoções, bem como imagens e símbolos. O primeiro estágio, o compartilhamento de conhecimento, que gera a nova idéia ou o conceito a ser aplicado ao contexto do trabalho, é chamado de socialização. A fase inicial do processo é baseada no conhecimento tácito dos indivíduos, mas já na sua gênese embuti o sentido de equipe, de busca conjunta de uma solução inovadora. Este acaba sendo explicitado por uma metáfora ou analogia, na etapa de externalização, que gera um conhecimento conceitual. A empresa tenta então combinar o novo conhecimento com o conhecimento, no caso explícito, previamente existente na organização, de modo a dar origem a um conhecimento sistêmico; essa etapa é chamada de combinação. A etapa seguinte é a de internalização, que ocorre quando o conhecimento explícito é transformado em tácito através do seu uso. Isso gera o que Huber chamou de "memória organizacional”, estando portanto relacionado ao learning-by-doing.

A espiral de criação do conhecimento organizacional é promovida através de cinco condições organizacionais: intenção; autonomia; flutuação e caos criativo; redundância - a abordagem do time de rúgbi; e variedade de requisitos. Este modelo de Cinco Fases do Processo de Criação do Conhecimento 
Organizacional ganha robustez na etapa de justificação do conceito, antes da construção do arquétipo, quando este é transformado em algo tangível ou concreto, passando pela difusão interativa do conhecimento em um nível ontológico superior (Nonaka \& Takeuchi, 1997). Um dos pilares desse modelo é o compartilhamento do conhecimento tácito e a busca da explicitação de um novo conceito.

\subsubsection{Modelo de Kim (Experiência Coreana)}

No processo de capacitação e aprendizado tecnológico, que ocorreram durante o esforço de industrialização da Coréia, houve um planejamento governamental, de longo prazo, para desenvolver a sua forte base industrial. Foram estabelecidas políticas públicas coerentes e harmoniosas, que reforçavam a capacitação tecnológica, através de um forte investimento em ensino. Ademais, ocorreram elevados investimentos em P\&D, quer seja governamental, quer seja no setor privado, através de incentivos e políticas facilitadoras traçadas pelo governo. Outro aspecto importante é que a indústria coreana se mobilizou para atender o mercado externo, tendo que se posicionar competitivamente para exportar seus produtos.

Para descrever a trajetória coreana de capacitação tecnológica para a sua industrialização, a abordagem de Kim (1999) toma como base, de um modo muito engenhoso, o modelo de Utterback. Mostra a dinâmica desse processo e a evolução dele ao longo do tempo, considerando aspectos críticos como a base de conhecimento existente e a intensidade do esforço, que são determinantes para a capacidade de absorção tecnológica.

São representados os fluxos de transferência de tecnologia que ocorreram nas distintas fases de capacitação tecnológica na Figura 2. Inicialmente, a Coréia absorveu tecnologias da fase específica, ou seja, bem maduras, e se limitou a praticar a simples imitação. Posteriormente começa a se empenhar na transferência de tecnologias da fase transitória, ou seja, tecnologias em estágio intermediário, e a praticar a imitação criativa. Finalmente atinge o estágio em que suas empresas já acumularam conhecimento e experiência suficiente para começar a inovar e a cooperar com empresas de ponta na fase fluida de desenvolvimento de uma tecnologia. 
FIGURA 2

Modelo de Kim: fluxos de transferência de tecnologia

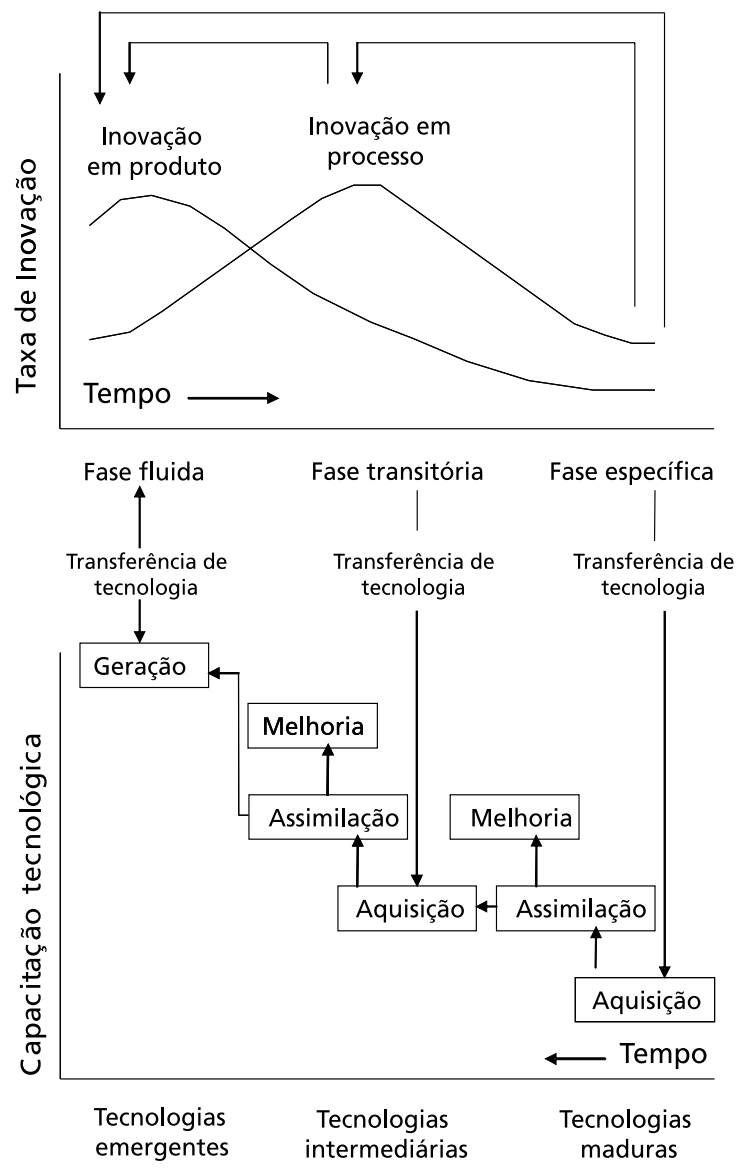

Fonte: Kim (1999), Fig.1.

As transferências de tecnologia, dependendo da fase em questão, são de naturezas distintas. A que ocorre na fase específica se caracteriza pela assimilação de conhecimentos operacionais. Condiçôes bem diferenciadas de transferência acontecem nas fases posteriores, por exemplo, a absorção e a captação de conhecimentos de tecnologias emergentes, ou na fase fluida, normalmente se dão via aquisições, fusões, alianças estratégicas ou consórcios de pesquisas pré-competitivas (Kim, 1999). 


\section{0 desenvolvimento da tecnologia de $F C C$ e sua importância no esquema de refino}

A maior parte das refinarias brasileiras foi construída nas décadas de 1960 e 70 , sendo concebidas para processar petróleos importados. Com o aumento significativo da produção brasileira de petróleo, o parque de refino sentiu a necessidade de dispor de maior capacidade de unidades de conversão, devido às características do óleo nacional que é mais pesado.

A principal unidade de conversão do refino brasileiro é o $F C C$, existindo 14 unidades no país. Estas foram implantadas, adquirindo-se tecnologias de licenciadores internacionais, a menos da modernização da unidade da Refinaria de Capuava, SP, e das duas últimas unidades construídas, na Refinaria Landulfo Alves de Mataripe, BA, e na Refinaria Alberto Pasqualini, RS, que se destinam ao processamento de cargas residuais, cujos projetos de engenharia básica e projeto executivo foram totalmente nacionais.

A unidade de FCC tem a importante função de converter gasóleo pesado de vácuo em fraçôes mais leves, na faixa dos combustíveis como GLP - o gás de cozinha; gasolina; e diesel. Isso propicia uma melhor adequação ao perfil de demanda de derivados. Esse tipo de unidade, se adaptados seu processo e catalisador, poderá processar cargas compostas com a adição de algumas fraçôes residuais do refino. Nesse caso, passa a ser chamada de unidade de RFCC.

No início da década de 1980, devido ao segundo choque do petróleo, que incitou o uso de energias alternativas e provocou uma recessão, aliado ao fato de estar aumentando a produção e o processamento de petróleos nacionais mais pesados, o Brasil passou a ter um excesso de disponibilidade de óleo combustível. Foi criado então o Programa Fundo de Barril, que visava maximizar a conversão das frações residuais do petróleo, obtendo um rendimento maior de combustíveis nobres. Iniciou-se a adequação das unidades de refino para esse fim.

A adição de frações residuais à carga das unidades de $F C C$ até então não era praticada, constituindo-se esta basicamente de gasóleo. Como existia uma folga de capacidade nas unidades de FCC, estas naturalmente foram escolhidas para processar o excesso de resíduo de vácuo, corrente majoritária do pool de óleo combustível. A Petrobras hoje tem posição de liderança nessa prática, 
pois a média nacional de adição de correntes residuais ao FCC se aproxima a $30 \%$, valor muito maior que a média mundial. Isso resulta num ganho de cerca de 1 dólar por barril processado, o que corresponde atualmente a mais de 500 mil dólares por dia de rendimento adicional no complexo de refino brasileiro (Leite, 2005).

\subsection{0 processo de $F C C$}

Esse processo, que surgiu na década de 1940, se baseia na fluidização e circulação do catalisador sólido. A matéria-prima, o gasóleo, proveniente da destilação a vácuo, após recuperar calor de correntes quentes do processo, entra em contato com o catalisador a uma temperatura elevada, ocorrendo a ruptura (cracking) das cadeias moleculares, dando origem a uma mistura de hidrocarbonetos que são posteriormente fracionados. São produzidos principalmente GLP e gasolina, além de outras frações como o LCO, que poderá sofrer tratamento posterior para integrar o pool de diesel, e o óleo decantado, que normalmente é destinado ao pool de óleo combustível ou vendido como resíduo aromático.

O craqueamento catalítico ocorre no reator, num tubo com fluxo ascendente, que é chamado de riser, onde se dá um íntimo contato entre a carga e o catalisador, ocorrendo o rompimento das cadeias hidrocarbônicas longas, sendo gerados compostos mais leves. Durante a reação, há formação de um resíduo de alto teor de carbono, chamado de coque, que se deposita na superfície do catalisador. Para que a atividade catalítica não seja prejudicada, tornase necessária a remoção do coque formado, o que é feito via sua combustão.

Após o reator, o catalisador gasto é separado dos produtos de reação, no vaso de separação. Os vapores de óleo tendem a saturar os poros do catalisador e, conseqüentemente, este deve ser retificado com vapor d'água antes de ir ao regenerador, onde se processa a queima do coque. Essa operação se passa no retificador, que fica na base do vaso de separação.

O catalisador regenerado se encontra a temperatura elevada e retorna à base do reator, ficando assim estabelecida uma contínua circulação, que se torna possível devido à diferença de pressão entre o regenerador e o reator.

Os efluentes gasosos do reator, constituídos de hidrocarbonetos craqueados, gases inertes e vapor d'água, são separados do catalisador gasto no 
final do riser, por meio de diferentes dispositivos de separação e ciclones. São então direcionados para a área de fracionamento, onde são separados nos diferentes cortes de produtos.

O catalisador virgem, na forma de um pó muito fino, é adicionado ao regenerador. A carga injetada na base do riser, ao entrar em contato com o catalisador quente, vindo do regenerador, vaporiza instantaneamente. Nas zonas de reação e regeneração, o catalisador é mantido em suspensão pela passagem de gases através da massa de catalisador.

Além das seções de conversão e de fracionamento já citadas, há também a seção de recuperação de gases, bem como poderá existir uma seção de tratamentos dos produtos, visando enquadrá-los às especificações dos combustíveis. Esse trabalho foca a seção de conversão, que é a de maior complexidade, encerrando o coração da tecnologia, sendo de vital importância na unidade de FCC e, por conseguinte, foi onde a Petrobras concentrou esforços de desenvolvimento tecnológico. Na Figura 3 é apresentado o desenho de um conversor de FCC, modelo PAC ${ }^{\mathrm{RC}}$ (Petrobras Advanced Converter: Residue Cracking).

FIGURA 3

Conversor de FCC: modelo PACRC

(Petrobras Advanced Converter: Residue Cracking)

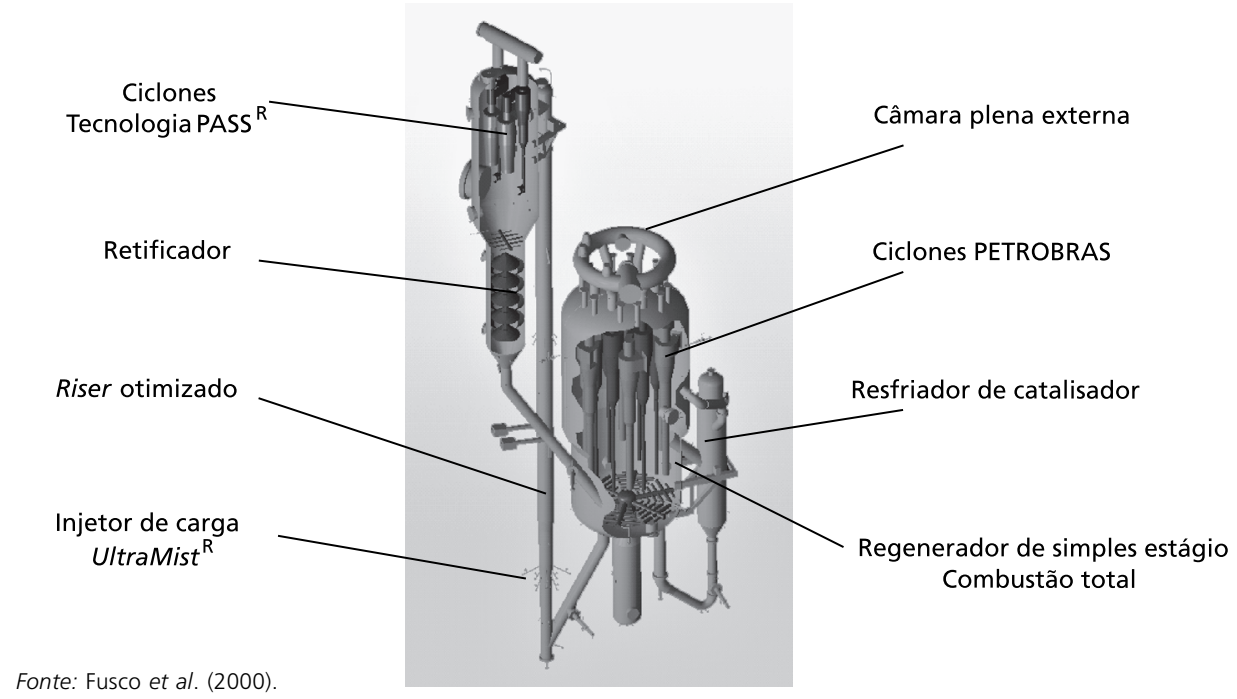


Os principais desafios tecnológicos para o processamento de cargas residuais no FCC são:

- separação rápida do catalisador gasto dos produtos de reação, para evitar reações indesejáveis e craqueamento térmico;

- injetores de carga especiais para melhorar o contato entre a carga e o catalisador, reduzindo o craqueamento térmico e a formação de coque;

- projeto otimizado do riser para melhoria de rendimento;

- catalisadores especiais, para aumentar a difusão e a acessibilidade aos seus sítios ácidos, reduzir o efeito deletério dos metais pesados contidos na carga, redução da tendência à formação de coque e preservação da estabilidade da gasolina produzida;

- ciclones especiais para redução da emissão de material particulado.

\subsection{A trajetória de desenvolvimento da tecnologia de $F C C$ (ou trajetória de construção de conhecimento sobre a tecnologia de $F(C)$}

A trajetória de construção de conhecimento e evolução da tecnologia de craqueamento catalítico na Petrobras pode ser dividida em basicamente duas grandes etapas: aquisição e assimilação de conhecimento externo; e transformação e geração de conhecimento interno. Ambas as etapas podem ser subdivididas ainda em duas fases mais específicas, de modo que se tenha uma trajetória tecnológica composta por quatro fases:

- aquisição e assimilação de conhecimento externo:

- aprendizado operacional;

- aquisição;

- transformação e geração de conhecimento interno:

- consolidação;

- domínio.

Essa divisão em quatro fases foi sugerida por Castillero et al. (1994), profissionais da administração central da Petrobras envolvidos com a tecnologia 
de FCC, num trabalho apresentado no congresso da Conexpo Arpel em 1994, em que foram detalhadas as três primeiras fases dessa trajetória, mostrando o grau de maturidade atingido e sugerido o limiar de uma nova fase com pleno potencial de exploração do conhecimento acumulado pela organização. Essa divisão parece bem apropriada à trajetória de desenvolvimento da tecnologia de FCC na Petrobras. A Figura 4 ilustra essa trajetória de acumulação e construção de conhecimento sobre essa tecnologia, ao longo do tempo.

FIGURA 4

Evolução do conhecimento sobre a tecnologia de FCC na Petrobras

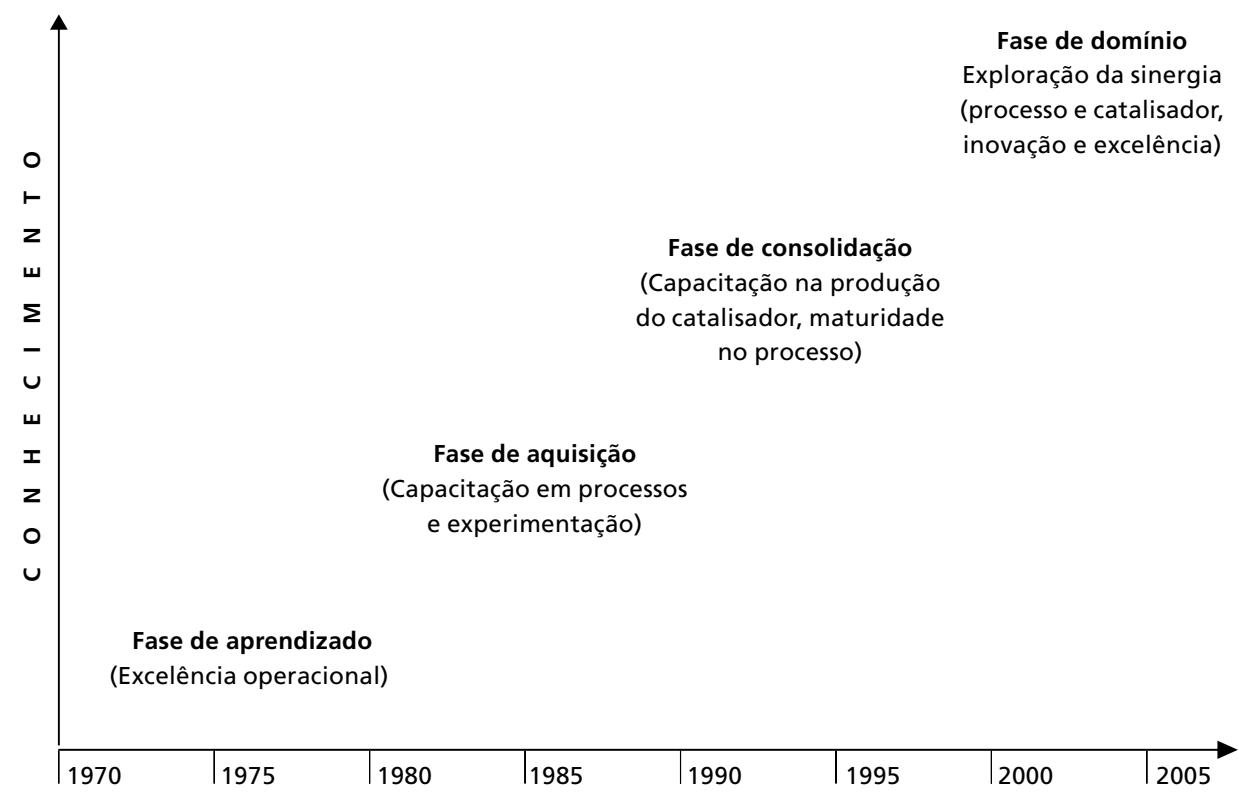

Fonte: elaboração própria.

\subsubsection{Fase de aprendizado operacional (learning-by-using)}

A Petrobras, logo após a sua criação em 1953, preocupou-se com a formação de seus quadros técnicos, organizando e implantando o Curso de Refinação de Petróleo de padrão internacional. Foram trazidos, para sua administração e 
corpo docente, expoentes das universidades e de indústrias dos países desenvolvidos (Leitão, 1985).

A primeira etapa, a fase de aprendizado operacional sobre FCC, caracterizou-se pela compra da tecnologia de tradicionais licenciadores e sua implementação nas refinarias, por meio da construção e montagem das unidades comerciais e da capacitação do corpo técnico para a partida e a operação delas. Adquiriram-se principalmente tecnologias da Kellogg (Orthoflow B, C e F) e da UOP (Side by side, Stacked e HTR). Nessa época, o foco empresarial era dado à continuidade operacional e à acumulação de conhecimento, objetivando atingir um elevado padrão operacional.

Apesar da ênfase operacional, em 1963, a Petrobras criou o seu Centro de P\&D, o CENPES, e implantou laboratórios e plantas-piloto para apoiar os trabalhos na área de FCC. A implantação do parque de refino e a experiência de construção, partida e operação de muitas unidades possibilitaram à empresa adquirir informação, tecnologia e know-how sobre alguns processos de refino e petroquímica, experiência que foi coroada com a criação da Superintendência de Engenharia Básica, em 1976, que objetivava facilitar a concretização das atividades de $\mathrm{P} \& \mathrm{D}$ e agilizar sua colocação no meio produtivo.

\subsubsection{Fase de aquisição (learning-by-doing)}

Um marco para o início dessa fase foi a assinatura do Acordo de Cooperação Técnica com a Pullman Kellogg, em 1977. Esse acordo estabelecia as condições de colaboração em $\mathrm{P} \& \mathrm{D}$ e projetos conceituais em alguns processos de refino, priorizando a área de craqueamento catalítico. A Kellogg se comprometia em fornecer pessoal qualificado para efetuar a transferência de tecnologia à Petrobras e prestar assistência para um projeto básico de $F C C$, que seria executado conjuntamente, no CENPES.

No nível operacional o que caracterizou uma mudança significativa, nessa nova fase, foi a necessidade de craquear cargas mais pesadas. No início dos anos 1980, começa a adição à carga convencional da unidade, o gasóleo de vácuo, de pequenas quantidades de frações pesadas e refratárias ao craqueamento como o resíduo de vácuo e o gasóleo de coque. Conseqüentemente podemos caracterizar essa etapa como learning-by-doing, pois a área operacional estava ousando experimentar. 
As ferramentas de captação de informação e conhecimento se expandem e se diversificam, fazendo-se uso intenso de literatura técnica, convênios com projetistas, consultorias, assessoria técnica a projetos, assessoria de fabricantes de catalisadores, seminários internos e externos, intercâmbio internacional, apropriação sistemática da experiência operacional, pesquisa de processo e de catalisadores em laboratórios e plantas-piloto e experimentação no nível operacional de melhorias de processo e catalisadores (Castillero et al., 1994).

\subsubsection{Fase de consolidação}

Essa fase começa com a decisão estratégica da Petrobras de ampliar seu escopo de atuação, entrando na produção de catalisadores de craqueamento catalítico. Buscou-se dominar todas as áreas do conhecimento que englobam a tecnologia de FCC: operação, processo, catalisadores, equipamentos e engenharia. Foi criada a Fábrica Carioca de Catalisadores S.A. (FCC S.A.), em 1985, sendo estabelecidos vários acordos com a Akzo Nobel (atualmente Albemarle), com objetivo de implantar essa unidade de produção de catalisadores de FCC na zona industrial de Santa Cruz, Rio de Janeiro.

Conjuntamente foi criada então a Divisão de Catalisadores do CENPES, visando absorver um conhecimento abrangente sobre o catalisador de FCC, através de um programa de capacitação na Akzo Nobel, que possibilitou o treinamento de vários engenheiros da FCC S.A., de técnicos e pesquisadores do CENPES e de engenheiros do então Departamento Industrial.

Paralelamente foi aprofundado o conhecimento na área de processo. A equipe de projetos da Engenharia Básica consolidou sua capacitação, tornando-se apta a projetar integralmente uma unidade de FCC. A Petrobras executou então projetos de modernização em todas as suas unidades existentes nas refinarias e implantou a Unidade Multipropósito de FCC, nas instalaçôes da Unidade de Negócio Six, em São Mateus do Sul, Paraná, que visava estudar parâmetros de engenharia para gerar dados para os projetos básicos dessa tecnologia.

$\mathrm{Na}$ operação atingia-se uma fase de plena maturidade, desenvolvendo simuladores e otimizadores de processo aplicáveis à previsão de rendimentos, ao planejamento da produção, às modificações e ao controle avançado das unidades. A operação passa a conhecer melhor a interação processo-equipa- 
mento-catalisador, gerando então melhores resultados comerciais (Castillero et al., 1994).

Ao longo do tempo, a Petrobras aumentava a produção de petróleos domésticos, principalmente do tipo Cabiúnas, que requeriam algumas adaptações do nosso parque de refino para um processamento rentável. Paulatinamente, adicionavam-se mais fraçôes residuais à carga das unidades de FCC. As novas descobertas apontavam para petróleos ainda mais pesados, do tipo Marlim, que produziam muito resíduo de vácuo, além de causar outros problemas ao refino, como maior acidez naftênica, instabilidade de alguns derivados etc.

\subsubsection{Fase de domínio - Criação do PROTER}

O refino sentia a necessidade de preparar-se melhor para o processamento majoritário de petróleos domésticos cujas características eram distintas dos petróleos até então importados. Foi criado então o Programa de Tecnologias Estratégicas do Refino - PROTER, em 1994, cujo principal objetivo era viabilizar o processamento de petróleo nacional de modo competitivo, com ênfase na conversão de frações residuais.

$\mathrm{Na}$ área de $F C C$, ou melhor, de $R F C C$, a meta era desenvolver um conversor Petrobras para o processamento de $100 \%$ de resíduo atmosférico (gasóleo + resíduo de vácuo) de petróleo pesado da bacia de Campos. Eram requeridas melhorias na formulação dos catalisadores, de modo a se obter aumento de atividade e de seletividade para o processamento de cargas mais pesadas.

Essa fase foi coroada com uma série de inovações em diversos itens do conversor de FCC, que foram sendo introduzidas e testadas separadamente nas unidades comerciais existentes, ao longo do tempo. Essas inovações aplicadas conjuntamente resultaram em uma nova concepção de projeto para o processamento de frações residuais num FCC, gerando a tecnologia PAC ${ }^{\mathrm{RC}}$ (Petrobras Advanced Converter: Residue Cracking) (Fusco et al., 2000).

$\mathrm{O} \mathrm{PAC}^{\mathrm{RC}}$ engloba as seguintes inovações tecnológicas (Leite et al., 2002):

- tecnologia proprietária do sistema de separação rápida, baseada em ciclones fechados, PASS (Petrobras Advanced Separation System), que 
aumenta o rendimento de gasolina em até $5 \%$ em peso - patentes US 5,665,949 e US 5,569,435;

- injetor de carga patenteado ULTRAMIST, que facilita um íntimo contato entre carga e catalisador - patente WO 01/44406;

- projeto otimizado do riser, o reator de FCC, via estudos fluido-dinâmicos;

- simulador/otimizador proprietário SIMCRAQ ${ }^{\mathrm{OT}}$, que engloba as distintas características e os novos dispositivos desenvolvidos pela Empresa;

- sistema catalítico para processamento de resíduos - patentes BR PI 9704925, PI 0100680 e WO 02/066163;

- aditivo à base de ZSM-5 para o aumento da produção de GLP e olefinas leves, adaptado para o processamento de resíduos - patentes BR PI 8506248 e PI 8606367;

- desenvolvimento de matrizes especiais para captura de metais pesados, que melhoram a atividade e o rendimento em produtos nobres - patente US 6,319,393;

- nova tecnologia de fabricação de catalisador, AMETHYST, que resulta num aumento significativo de acessibilidade às grandes moléculas;

- otimização de ciclones para redução de emissão de material particulado pela chaminé e para evitar perda do inventário de catalisador - patente CA-2,396,183.

A combinação dessas melhorias e inovações tornou possível o projeto de três novas unidades de RFCC, que processam resíduo atmosférico, tais como:

- RECAP, Refinaria de Capuava, São Paulo: capacidade de $3 \mathrm{mil} \mathrm{m} 3 / \mathrm{d}$ de resíduo atmosférico de petróleo Albacora. Partida em dezembro de 1999;

- RLAM, Refinaria Landulpho Alves de Mataripe, Bahia: capacidade de 10 mil m³. Partida em abril de 2001;

- REFAP, Refinaria Alberto Pasqualine, Rio Grande do Sul: 7 mil m²/d. Partida em setembro de 2006.

Essas unidades processam cargas residuais extremamente refratárias ao craqueamento e, apesar disso, apresentam elevados níveis de conversão e rendimento em gasolina. Essas três unidades são altamente rentáveis por proces- 
sarem cargas de baixo valor econômico, sendo o tempo de retorno de seu investimento de aproximadamente dois anos.

\section{Metodologia proposta para análise}

Pela descrição das distintas fases da trajetória de desenvolvimento da tecnologia de FCC, vê-se que a tecnologia de processo foi absorvida e assimilada anteriormente à tecnologia de catalisadores, a qual, pela divisão temporal, só aconteceu na fase de consolidação. Conseqüentemente sugerimos que a análise seja executada em dois universos distintos: aprendizagem e dinâmica de inovação, isto é, análise das primeiras etapas da trajetória de evolução tecnológica que compreendem as fases de aprendizado operacional, aquisição e consolidação, estas, no que tange à capacitação na área de formulação e fabricação de catalisador de $F C C$, deverão ser trabalhadas segundo modelos de aprendizagem organizacional consagrados. Para as etapas finais do processo, a fase de consolidação, no que diz respeito ao processo de FCC, e de domínio, nesse caso abarcando tanto tecnologia de processo como de catalisadores, será analisada sob a ótica dos modelos de dinâmica da inovação, tendo como objetivo verificar qual modelo melhor explica a trajetória percorrida pela Petrobras.

Para a análise da etapa de aprendizagem vivenciada pela Petrobras, como estamos tratando um universo de três modelos, não fica difícil se fazer uma comparação direta entre os conceitos e os demais aspectos presentes ao longo da trajetória percorrida pela empresa e pelo modelo per se, de modo a estabelecer suas similitudes e discrepâncias.

Para os modelos de dinâmica de inovação, como temos um número maior, sugere-se a aplicação de critérios para analisar a aderência de trajetória ao modelo. Esses critérios são:

- natureza e conceito do modelo: a concepção básica do modelo;

- estrutura do modelo: atividades (ou áreas de atuação) e atores envolvidos;

- macrofluxo do modelo: interação e comunicação entre os diversos atores (ou áreas de conhecimento). 
Com vistas a facilitar o processo de análise para cada critério, será avaliado o quanto a trajetória em estudo se adequou ao modelo. Por conseguinte cada item será pontuado como adequado, parcialmente adequado e discrepante.

\subsection{Adequação da trajetória tecnológica aos modelos de aprendizagem Organizacional}

O modelo de Nevis, DiBella e Gould difere do de Huber, pelo fato de que este evidencia uma etapa em que a informação é assimilada e interpretada, de modo que um novo conhecimento é incorporado à organização. Essa assimilação enriquecida é portadora de futuro à organização, considerando que, na medida em que o conhecimento é acumulado e o aprendiz se comporta como um receptor ativo, há maior chance de se gerar uma inovação. Os profissionais da área de $F C C$ costumam dizer que, para qualquer pergunta que se faça sobre $F C C$, a resposta é sempre “depende!”. Há uma gama de possibilidades, pois não existe a verdade absoluta. Isso dá margem à exploração de idéias, que a princípio possam parecer um tanto ousadas. Há muito espaço para discussão e a dúvida é natural. O que é verdade considerando quatro parâmetros do processo de $F C C$, talvez não o seja quando entra uma quinta variável na análise. Num ambiente de conhecimento complexo, como da tecnologia de FCC, a interpretação e a discussão sobre as informações disponíveis são essenciais para a aprendizagem.

$\mathrm{Na}$ área de $F C C$, pode-se afirmar que houve um grande investimento na capacitação e treinamento do pessoal e formação de massa crítica, pois, além do Curso de Engenharia de Processamento, normalmente ministrado para todos os novos engenheiros, ao entrar nos quadros da empresa, as distintas equipes de profissionais dessa área realizaram muitos treinamentos específicos e participaram de várias atividades de compartilhamento de experiências e executaram diversos trabalhos, ao longo de seu processo de capacitação. Se analisarmos esses eventos e fóruns de aprendizado, tomando como referência estágios da aprendizagem adotados por Huber, tais como aquisição, transferência do conhecimento (compartilhamento e disseminação), interpretação (assimilação) e utilização, pode-se compor um quadro sobre o processo de aprendizado desse grupo, como é mostrado na Tabela 1. 
TABELA 1

A capacitação da equipe de $F C C$ sob a ótica dos estágios de aprendizagem de Huber

\begin{tabular}{|c|c|c|c|c|c|}
\hline Equipes & Cursos e fóruns & Aquisição & Compartilhamento & Interpretação & Utilização \\
\hline \multirow[t]{10}{*}{ Operação } & Cursos funcionais e modulares & $x$ & $x$ & & \\
\hline & Encontros técnicos da comunidade ${ }^{1}$ & $x$ & $x$ & $x$ & $x$ \\
\hline & Intercâmbio com empresas projetistas & $x$ & $x$ & $x$ & \\
\hline & Licenciamento de tecnologia & $x$ & $x$ & & \\
\hline & Implantação das unidades operacionais & $x$ & $x$ & $x$ & $x$ \\
\hline & $\begin{array}{l}\text { Seminários com fabricantes de } \\
\text { catalisador e projetistas }\end{array}$ & $x$ & $x$ & & \\
\hline & Visitas técnicas & $x$ & $x$ & & \\
\hline & Palestras e cursos de consultores & $x$ & $x$ & & \\
\hline & Congressos e seminários & $x$ & $x$ & & \\
\hline & Monitoramento tecnológico & & $x$ & $x$ & \\
\hline \multirow{7}{*}{$\begin{array}{l}\text { Engenharia } \\
\text { básica }\end{array}$} & Desempacotamento de tecnologia & $x$ & $x$ & $x$ & $x$ \\
\hline & Transferência de tecnologia ${ }^{2}$ & $x$ & $x$ & $x$ & $x$ \\
\hline & Curso de fluidização & $x$ & $x$ & & \\
\hline & Projetos conjuntos com clientes & $x$ & $x$ & $x$ & $x$ \\
\hline & Projetos conceituais & & $x$ & $\mathrm{x}$ & $x$ \\
\hline & Congressos e seminários & $x$ & $x$ & & \\
\hline & Monitoramento tecnológico & & $x$ & $x$ & \\
\hline \multirow[t]{2}{*}{$P \& D$} & Projetos de P\&D & $x$ & $x$ & $x$ & $x$ \\
\hline & Transferência de tecnologia na Akzo Nobe & $x$ & $x$ & $x$ & $x$ \\
\hline \multirow[t]{9}{*}{ FCC S.A. } & Cooperação em P\&D c/ Akzo Nobel ${ }^{3}$ & $x$ & $x$ & $\mathrm{x}$ & $\mathrm{x}$ \\
\hline & Congressos e seminários & $x$ & $x$ & & \\
\hline & Monitoramento tecnológico & & $x$ & $x$ & \\
\hline & Treinamento na Akzo Nobel & $x$ & $x$ & $x$ & $x$ \\
\hline & $\begin{array}{l}\text { Contrato de engenharia básica e assist. } \\
\text { técnica à produção de catalisadores }\end{array}$ & $x$ & $x$ & $x$ & $x$ \\
\hline & $\begin{array}{l}\text { Fóruns de desenvolvimento/produção/ } \\
\text { marketing na Akzo Nobel }\end{array}$ & & $x$ & $x$ & $x$ \\
\hline & Seminários com a Petrobras & $x$ & $x$ & $x$ & \\
\hline & $\begin{array}{l}\text { Encontro Sul-Americano de } \\
\text { Craqueamento Catalítico }\end{array}$ & $x$ & $x$ & $x$ & \\
\hline & Monitoramento tecnológico & & $x$ & $x$ & \\
\hline
\end{tabular}

\footnotetext{
1 Fórum que discute as melhores práticas na área operacional.

2 Quando se adquiriu metodologias de projeto de processo e equipamentos de refino, bem como técnicas de gestão de projetos de engenharia básica.

3 Projetos em conjunto com os Centros de P\&D da Akzo Nobel, em Amsterdam (Holanda) e Pasadena (EUA).

Fonte: elaboração própria.
} 


\subsection{Análise da trajetória de evolução da tecnologia diante dos modelos de aprendizagem}

O processo vivenciado pela Petrobras parece ser mais aderente ao modelo de Huber, contendo igualmente as etapas de aquisição, transferência do conhecimento, interpretação e utilização, como sugere a Tabela 1. Entretanto se distancia dele no aspecto relativo à sua linearidade, pois as barreiras entre essas etapas do processo são fluidas, havendo feedback das etapas finais para as precedentes e sendo cada estágio influenciado pela base de conhecimento acumulada na organização. Na Figura 5, é proposto um diagrama de um modelo "modificado" de Huber, que parece ser mais aderente à experiência dessa empresa.

FIGURA 5

Modelo de aprendizagem da tecnologia de FCC: Huber "modificado"

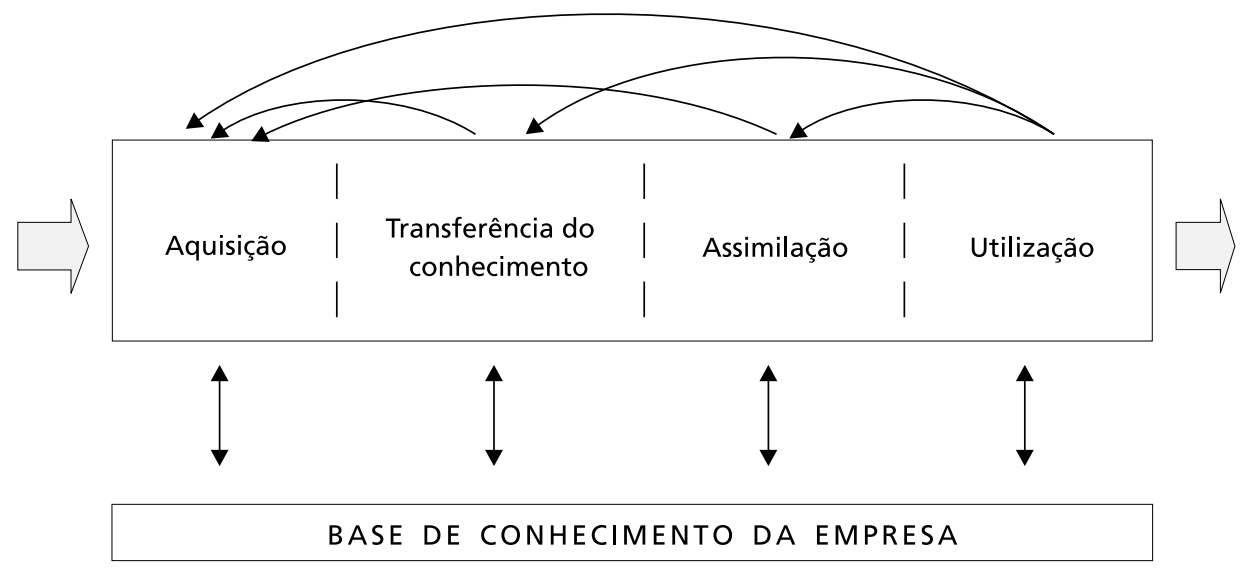

Fonte: elaboração própria.

Quanto à aderência à visão de learning organization, disseminada por Peter Senge, pode-se afirmar que dentre as cinco disciplinas quatro delas estiveram bem presentes ao longo de toda a trajetória de evolução tecnológica do FCC. A preocupação com a formação de recursos humanos sempre se fez presente como um valor na Petrobras e a maestria pessoal sempre foi algo cultivado na organização. Um aspecto importante é que o empregado da 
Petrobras sente que aprender é uma tarefa absolutamente prioritária para a Companhia. Os gerentes, especialistas e técnicos sempre tiveram como meta o seu desenvolvimento profissional e pessoal, pois o pioneirismo de diversas atividades requeria um esforço contínuo de aquisição de novos conhecimentos e habilidades (Leite, 2005).

Outra disciplina presente foi a da visão compartilhada, pois os objetivos do negócio e os desafios estavam claramente colocados e havia o engajamento do corpo de gerentes e técnicos de modo a concretizar e criar o futuro almejado, a obtenção da autonomia tecnológica na área de FCC.

Os trabalhos importantes desenvolvidos numa organização costumam ser fruto do aprendizado em equipe, de um esforço sinérgico em criar conhecimento e capacidades maiores que a soma dos talentos individuais. No caso da tecnologia de FCC, esse elemento esteve presente ao longo de todo o processo, pois todo o trabalho foi desenvolvido por equipes multidisciplinares. O diálogo, o pensar soluções coletivamente, que permitissem o surgimento de insights, que não ocorreriam individualmente, foi muito praticado.

O pensamento sistêmico também foi exercido, estabelecendo-se uma comunidade de prática na área de $F C C$, constituída por gente da operação, manutenção, inspeção, projeto, planejamento, engenharia, P\&D e administração, na busca de entender e modelar as inter-relações existentes no sistema de refino. Embora na época em que se iniciaram essas atividades não existisse de modo bem estruturado o Planejamento Estratégico da Petrobras, os objetivos do negócio e os desafios empresariais estavam claramente colocados e uma visão holística e abrangente era perseguida.

A disciplina de modelos mentais era incipiente na Empresa, podemos até afirmar que, no início do período em estudo, existia uma estrutura e uma mentalidade bastante hierarquizada na Companhia, dificultando o seu desenvolvimento. As mudanças organizacionais não ocorriam com freqüência, só recentemente, após a perda do monopólio e a inserção num mercado mais volátil e dinâmico, esse novo elemento começa a se delinear.

Pelo exposto, é válido afirmar que a maioria dos princípios da learning organization estiveram significativamente presentes ao longo da trajetória de construção de conhecimento sobre a tecnologia de FCC experimentada pela Petrobras. 


\section{0 caso do desenvolvimento da tecnologia de $F C C$ sob a ótica da dinâmica da inovação}

Será realizada uma análise da aderência da segunda etapa da trajetória tecnológica percorrida pela Petrobras aos modelos de dinâmica da inovação consagrados na literatura. Entretanto, inicialmente para caracterizar bem a trajetória de evolução tecnológica percorrida por vários países em desenvolvimento e que igualmente foi seguida pela Petrobras, é interessante fazer referência a alguns trabalhos que discutem o assunto e propõem um modelo específico. Este não é universal e nem é um modelo muito conhecido, embora reflita bem o esforço de desenvolvimento de diversas tecnologias na área de refino.

\subsection{A trajetória tecnológica de países em desenvolvimento: da operação à inovação}

Um trabalho antigo de Kim (1980) cita que o processo de desenvolvimento industrial pode ser modelado em três estágios: implementação, assimilação e melhoramento. Segundo o autor, a participação de uma instituição de P\&D é muito importante ao longo do processo, pois esta executa funçóes de consultoria no estágio de implementação, de desenvolvimento adaptativo no de assimilação e, finalmente, de P\&D, sua atribuição mais nobre, no estágio de melhoramento.

Leitão (1985), estudando a trajetória de aprendizado tecnológico no refino brasileiro, argumenta que, nos países de industrialização tardia, o processo de inovação tecnológica se baseia mais na inovação incremental, que resulta na adaptação de tecnologias existentes às novas condições de mercado e matériaprima. Isso ocorre até que se atinja um nível de capacitação que se possa enveredar pelo caminho das inovações radicais. Muitas vezes essa condição não é atingida, pois as empresas de países periféricos se posicionam no mercado de modo acanhado, explorando vantagens competitivas como matériaprima e mão-de-obra mais barata, não procurando agregar conhecimento ao seu negócio.

Sanjaya Lall (1980 e 1982) analisa a situação na Índia, concluindo também que os países em desenvolvimento são, claramente, imitadores e adaptadores 
de tecnologia, em lugar de inovadores. O processo de aprendizado é por ele classificado em três níveis: elementar - aprendizado operacional e pequenas adaptaçôes; intermediário - cópia e aperfeiçoamento de processos e produtos; e avançado - compreendendo os projetos integrados e a inovação.

Esses autores corroboram com um modelo que se inicia com a importação de uma tecnologia e a busca de capacitação no nível operacional, de modo a se produzir eficientemente. Depois o processo segue a sua evolução, normalmente passando pelos estágios de imitação e cópia, adaptação e melhoria, até chegar à geração de novas concepções tecnológicas, ou seja, à inovação. Esse caminho foi também plenamente percorrido pela Petrobras, no que tange ao desenvolvimento da tecnologia de FCC. Na Figura 6, apresentamos essa trajetória de desenvolvimento, normalmente praticada pelos países em desenvolvimento. A intenção de abordar esse assunto advém do fato de que os modelos de dinâmica da inovação discutidos e consagrados na literatura são concebidos em países desenvolvidos, o que dificulta uma boa aderência da experiência vivenciada por empresas de países em desenvolvimento.

FIGURA 6

Trajetória de evolução tecnológica nos países em desenvolvimento

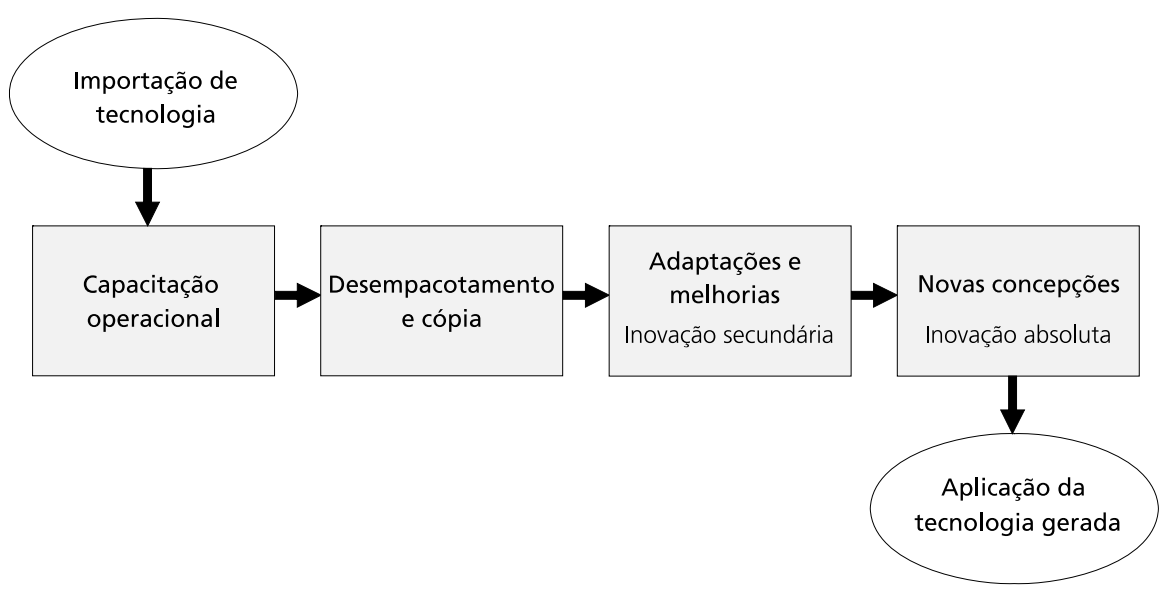




\subsection{Análise da aderência aos modelos de dinâmica da inovação}

Modelos lineares quanto ao grau de autonomia da atividade inventiva Technology Push e Demand Pull, como Dosi (1982) os discutiu, são muito difíceis de serem aplicados de modo puro, isolando-se totalmente o efeito da demanda de mercado da oferta de conhecimento. Os mecanismos do mercado exercem grande influência na seleção ex ante da trajetória tecnológica a ser seguida. Isso também ocorreu, predominantemente, na área de FCC. Por outro lado, no julgamento das opções tecnológicas, sempre se recorre a diferentes possibilidades que levam em consideração a experiência e o conhecimento acumulado, além de outros fatores institucionais e sociais.

No caso em estudo, esses tipos de modelos simples seqüenciais não espelham a prática, tendo em vista a complexidade da tecnologia, o número de agentes envolvidos, a importância do conhecimento acumulado, as demandas do mercado e as necessidades operacionais. Por conseguinte, ao se aplicar a metodologia de análise e os critérios sugeridos - natureza e conceito; estrutura; e macrofluxo do modelo -, todos são discrepantes.

\section{Modelo de Terceira Geração}

Natureza e conceito: é um modelo de processo logicamente seqüenciado que leva em consideração mercado e tecnologia, sendo uma evolução em relação aos modelos lineares. Entretanto não é contínuo, o que se afasta do caso em estudo (parcialmente adequado).

Estrutura: há aderência às atividades e aos atores descritos, incluindo inclusive atores externos à organização (adequado).

Macrofluxo: concebe uma complexa rede de comunicação intra e extraorganizacional, mas apresenta fronteiras estanques entre os atores, parecendo um processo com fluxo intermitente (parcialmente adequado).

\section{Modelo de Kline e Rosenberg}

Natureza e conceito: é um modelo do processo que enfatiza as interações entre as distintas fases do processo, dando ênfase à cadeia de inovação, não havendo limites rígidos entre seus elementos, tendo como ponto de partida as necessidades de mercado (adequado). 
Estrutura: as atividades e atores descritos são adequados, mas não considera o conceito de empresa expandida, em que clientes, fornecedores e outros parceiros tecnológicos participam ativamente da cadeia de inovação (parcialmente adequado).

Macrofluxo: o modelo enfatiza a interação e comunicação contínua entre os elementos da cadeia (adequado).

\section{Modelos de Quarta e Quinta Geração}

Natureza e conceito: são modelos mais ligados à gestão do processo de inovação, que se aplicam ao sistema de desenvolvimento de produto, principalmente produtos montados, e sua "manufaturabilidade", no caso da Quarta Geração, e flexibilidade no design e economia de escala e escopo, no caso da Quinta Geração. Por conseguinte, o caso em estudo difere por ser mais focado em inovação em processo, embora haja também a existência de um produto, o catalisador, mas mesmo assim também não se aplicam os conceitos (discrepante).

Estrutura: não há aderência às plataformas de inovação, considerando as atividades e atores, no modelo da Quarta Geração, e principalmente os leadingedge users, no modelo da Quinta Geração (discrepante).

Macrofluxo: intensa interação e comunicação entre os diversos atores (adequado).

\section{Modelo de Utterback}

Natureza e conceito: este é um modelo preferencialmente relacionado à economia da inovação, que descreve sua dinâmica para a produção de produtos industriais montados e não-montados. É feita uma divisão temporal, baseada na evolução do mercado e suas conseqüências sob o processo de inovação, em suas três fases: fluida, transitória e específica. Como o caso em estudo trata principalmente do desenvolvimento de um processo de refino e o processo comercial de FCC já se encontrava em fase madura, quando a Petrobras começou suas inovações, ou seja, já se encontrava na fase específica, não está pertinente ao seu conceito (discrepante).

Estrutura: todos os atores e atividades estão descritos de um modo abrangente, mas num contexto distinto (discrepante).

Macrofluxo: idem (discrepante). 


\section{Modelo de Nonaka e Takeuchi}

Natureza e conceito: é um modelo do processo de inovação, que ocorre de modo contínuo, incremental e em espiral. Um dos pilares desse modelo é o compartilhamento do conhecimento tácito e a busca da explicitação de um novo conceito. A próxima etapa é a combinação do novo conhecimento tácito com o explícito, previamente existente na organização, de modo a dar origem a um conhecimento sistêmico; essa etapa é chamada de combinação. Em muitos momentos, ao longo dos desafios que a comunidade de FCC da Petrobras enfrentou, essa prática se fez presente. O conhecimento explicitado é então internalizado, tornando-se num novo conhecimento tácito através de seu uso (parcialmente adequado).

Estrutura: o modelo difere no que tange às condições organizacionais, que este afirma serem cinco: intenção, autonomia, flutuação e caos criativo, redundância e variedade de requisitos. A cultura brasileira é distinta e bem mais individualista que a oriental. A flutuação e o caos criativo vão contra a cultura de "em time que está ganhando não se mexe", tem-se o hábito de enfrentar crises, mas não de criá-las ou induzi-las em busca de um futuro melhor. Quanto ao aspecto da redundância, a abordagem do time de rúgbi, é um tanto estranho ao nosso meio (discrepante).

Macrofluxo: mais uma vez a cultura é diferenciada: a comunicação intensa e a busca de consenso, principalmente na etapa de planejamento, é base do modelo japonês. Além disso, a conquista de níveis ontológicos superiores na organização - processo que progride em espiral, envolvendo toda a organização, tem com base uma filosofia comunitária que privilegia o longo prazo. Por conseguinte, a cultura de improvisação e uma boa dose de imediatismo existente no contexto brasileiro impedem a aderência ao modelo (discrepante).

\section{Modelo de Kim}

Natureza e conceito: explicita os fluxos de transferência da tecnologia, ou seja, é um modelo de capacitação para o processo de inovação que ocorreu durante o esforço de industrialização da Coréia, que foi distinto do caso brasileiro, porque a Coréia buscou nessa etapa tornar-se competitiva, pois visava conquistar o mercado externo para seus produtos. O caso brasileiro foi calcado num modelo de substituição de importaçóes para atendimento do mercado interno. 
No caso coreano, na medida em que as empresas se capacitavam, passavam a importar tecnologia na fase transitória, até chegar a um nível de conhecimento e experiência acumulados, que começaram a inovar e cooperar com empresas de ponta na fase fluida de desenvolvimento de tecnologia. No caso da tecnologia de FCC, foram importadas tecnologias de processo totalmente maduras, na fase específica. No caso da tecnologia de desenvolvimento de catalisadores, foram transferidas algumas tecnologias na fase transitória, mas não na fase fluida (parcialmente adequado).

Estrutura e macrofluxo: esse modelo tem uma característica distinta, não explicitando as atividades e os atores da inovação, bem como o fluxo de comunicação, inter-relações e interdependências. É chamado como o Modelo de Inovação da Coréia, mas na realidade mais se assemelha a um modelo de capacitação e aprendizado, que no caso foi distinto do brasileiro nestes últimos anos, embora tenha sido parecido num passado distante (discrepante).

A Tabela 2 apresenta uma consolidação da análise executada, que mostra que, dentre os modelos analisados, a experiência vivenciada pela Petrobras mais se aproxima do modelo de Kline e Rosenberg, embora também não apresente uma aderência total.

TABELA 2

Consolidação da análise de aderência da trajetória tecnológica aos modelos de dinâmica da inovação

\begin{tabular}{lccc}
\hline Modelo & Natureza e conceito & Estrutura & Macrofluxo \\
Ofertista & Discrepante & Discrepante & Discrepante \\
Linear reverso & Discrepante & Discrepante & Discrepante \\
Terceira Geração & Parcialmente adequado & Adequado & Parcialmente adequado \\
Kline e Rosenberg & Adequado & Parcialmente adequado & Adequado \\
Quarta e Quinta Geração & Discrepante & Discrepante & Adequado \\
Utterback & Discrepante & Discrepante & Discrepante \\
Nonaka e Takeuchi & Parcialmente adequado & Discrepante & Discrepante \\
Kim & Parcialmente adequado & Discrepante & Discrepante \\
\hline
\end{tabular}

Fonte: elaboração própria. 


\section{Conclusões}

A trajetória de construção de conhecimento na área de $F C C$, em sua fase inicial, mostrou-se mais aderente ao Modelo de Aprendizagem de Huber. Entretanto se distanciou do modelo original quanto ao aspecto de linearidade, pois as barreiras entre as etapas do processo eram frágeis, havendo feedback das etapas finais para as precedentes, sendo cada estágio influenciado pela base de conhecimento acumulada na organização. Seria mais correto falar em um modelo de Huber "modificado".

Considerando a visão de learning organization, pode-se dizer que quatro dentre as cinco disciplinas de Peter Senge estiveram presentes ao longo da trajetória tecnológica do desenvolvimento de $F C C$, que são: a maestria pessoal, a visão compartilhada, a aprendizagem em equipe e o pensamento sistêmico. Uma boa dose do sucesso obtido no desenvolvimento da tecnologia de FCC pode ser imputada à visão sistêmica, pois a decisão estratégica de atuar na área de desenvolvimento e produção de catalisadores, passando a conhecer melhor a interação processo-equipamento-catalisador, foi essencial para a consecução dos objetivos e superação dos desafios tecnológicos nessa área. A aderência ao modelo de Senge não foi total, pois, na disciplina do modelo mental, as condições internas à organização não permitiram o seu florescimento.

Quanto aos modelos de dinâmica da inovação consagrados na literatura, a trajetória de inovação vivenciada pela Petrobras e pela Fábrica Carioca de Catalisadores S.A. foi mais aderente ao modelo descrito por Kline e Rosenberg, que enfatiza as interações entre as diferentes fases do processo, não havendo limites rígidos entre os elementos da cadeia de inovação. Outro aspecto importante desse modelo é que a gênese das atividades de $\mathrm{P} \& \mathrm{D}$ advém de uma oportunidade de mercado. Na área de FCC, a grande maioria dos desenvolvimentos realizados tiveram essa origem ou visavam à solução de algum problema operacional. A opção de processar frações pesadas nas unidades de FCC, quando foi criado o Programa de Fundo de Barril e o de desenvolver um FCC para resíduos processando $100 \%$ de resíduo atmosférico, quando da criação do PROTER, tiveram como fonte necessidades de mercado, o que muito contribuiu para a eficiência desses programas tecnológicos. Essa decisão 
estratégica chegou a bom termo graças à grande incorporação de conhecimento de agentes externos, como clientes, fornecedores e parceiros, além de um monitoramento constante de informaçōes mercadológicas. As novas idéias ou projetos passaram pela sistemática de análise e seleção, através dos Comitês Tecnológicos Estratégicos e Operacionais da Petrobras, que tem como base o funil da inovação.

De um modo geral, a aderência da trajetória tecnológica em estudo aos modelos externos consagrados, como foi mostrado na Tabela 2, não foi muito grande. Isso mostra que a nossa realidade não espelha bem modelos alienígenas. Kim, Leitão e Lall descrevem um modelo que foi plenamente adotado pelos países em desenvolvimento, o qual inicia com a importação de uma tecnologia e a busca de capacitação no nível operacional, de modo a se produzir eficientemente. Depois o processo segue a sua evolução, normalmente passando pelos estágios de imitação e cópia, adaptação e melhoria, até chegar à geração de novas concepções tecnológicas, ou seja, à inovação, como ocorreu também na área de FCC.

\section{Referências bibliográficas}

Argyris, C.; Schön, D.A. Organizational learning: a theory of action perspective, Reading: Addison-Wesley, 1978.

Barbieri, J.C.; Álvares, A.C.T. “Organizaçōes inovadoras”, Inovaçôes nas organizaçôes empresariais, Rio de Janeiro: Editora da FGV, 2003.

Castillero, J.A.M.; Herrmann, C.C.; Schlosser, C.R.; Faria, J.L.M. "Tecnologia de craqueamento catalítico na Petrobras: análise da sua evolução e da validade econômico-estratégica do seu domínio", Conexpo Arpel, Rio de Janeiro, 1994.

Clark, K.B.; Wheelwright, S.C. Managing new product and process development: text and cases, Nova York: The Free Press, 1993. 
Dosi, G. "Technological paradigms and technological trajectories: a suggested interpretation of the determinants and directions of technical change", Research Policy, v.11, n.3, p.147-162, jun., 1982.

."The nature of the innovative process", in Dosi, G. et al., Technological change and economic theory, Londres, Brighton: Pinter Publishers, SPRU, University of Sussex, DCR Discussion Paper, 1988.

Fusco, J.M.; Einsfeldt, M.; Medeiros, J.; Freire, P.S.; Patrício Jr., N.; Tan, M.H.; Ramos, J.G.F.; Torem, M.A. "PAC ${ }^{\mathrm{RC}}$ : um marco no processo de craqueamento catalítico fluido", 4ํㅡㄹ Encontro Sul-Americano de Craqueamento Catalítico, Manaus, 14-17/8/2000.

Huber, G. "Organizational learning: the contribution process and literature", $O r$ ganization Science, v.2, p.88-115, 1991.

Kim, L. "Stages of development of industrial technology in a developing country: a model”, Research Policy, v.9, p.245-277, 1980.

. "Building technological capability for industrialization: analytical frameworks and Korea's experience", Industrial and Corporate Change, v.8, n.1, p.111136, mar., 1999.

Kline, S.J. "Innovation is not a linear process", Research Management, v.28, n.4, p.36-45, jul.-ago., 1978.

Kline, S.J.; Rosenberg, N. "An overview of innovation”, NAP, p.275-305, 1986.

Lall, S. "Developing countries as exporters of industrial technology", Research Policy, n.9, p.24-52, 1980.

. "Technological learning in the third world: some implications of technology exports", in Stewart, F.; James, J., The economics of new technology in developing countries, Londres: Frances Pinter Publishers, 1982.

Leitão, D.M. "O processo de aprendizado tecnológico nos países em desenvolvimento: o caso da refinação de petróleo no Brasil”, Boletim Técnico da Petrobras, Rio de Janeiro, v.28, n.3, p.207-218, jul.-set., 1985.

Leite, L.F.; Fusco, J.M.; Ramos, J.G.; Medeiros, J.; Torem, M.A. "Novel Fluid Catalytic Cracking Technology - Excellence in heavy feedstock processing", $17^{\text {th }}$ World Petroleum Congress, Rio de Janeiro, Brasil, 1-5/9/2002. 
Leite, L.F. Inovação: o combustivel do futuro, Rio de Janeiro: Qualitymark, 2005.

Levitt, T. "Marketing myopia", Harvard Business Review, p.30-44, set.-out., 1975.

Nevis, E.C.; DiBella, A.J.; Gould, J.M. "Understanding organizations as learning systems”, Sloan Management Review, p.73-84, winter, 1995.

Nonaka, I.; Takeuchi, H. Criação de conhecimento na empresa, Rio de Janeiro: Ed. Campus, 1997.

Petrobras/MG-EM-001. Descrição da Fase de Definição do Empreendimento (FEL), rev.2, 23/3/2004

Rothwell, R. "Towards the fifth-generation innovation process", International Marketing Review, v.11, n.1, p.7-31, 1994.

Senge, P.M. A quinta disciplina, São Paulo: Ed. Best Seller, 1990.

Tidd, J.; Bessant, J.; Pavitt, K. “Paths: exploiting technological trajectories”, Managing Innovation $2^{\text {nd }}$ Chap, 1997.

Utterback, J.M. Dominando a dinâmica da inovação, Rio de Janeiro: Qualitymark, 1996.

ENDEREÇOS PARA CORRESPONDÊNCIA:

Luiz Fernando Leite - Ileite@petrobras.com.br

Av. Rio Branco 1, $20^{\circ}$ andar, Centro, Petrobras/COMPERJ, Rio de Janeiro, RJ 20090-907

Tel: (21) 3487-6158

PeterSeidl-pseidl@eq.ufrj.br

Av. Horácio Macedo, 2030, Bloco E, Sala 204, Escola de Química - UFRJ, Rio de Janeiro, RJ 21941-909

Tel: (21) 2562-7586

Adelaide M. de Souza Antunes-adelaide@eq.ufrj.br

Av. Horário Macedo, 2030, Bloco I, sala 222, Escola de Química - UFRJ, Rio de Janeiro, RJ 21941-909

Tel: (21) 2562-7573 / 2562-7426 